\title{
A report on the outbreak of Zika virus on Easter Island, South Pacific, 2014
}

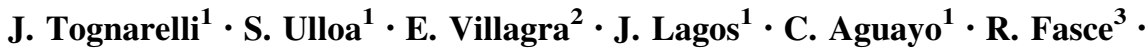

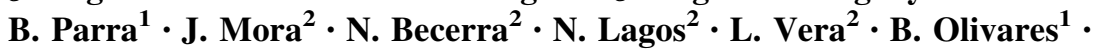 \\ M. Vilches ${ }^{2} \cdot$ J. Fernández ${ }^{1}$
}

Received: 30 September 2014/ Accepted: 17 November 2015/Published online: 26 November 2015

(c) Springer-Verlag Wien 2015

\begin{abstract}
Zika virus (ZIKV) is an emerging mosquitoborne flavivirus circulating in Asia and Africa. In 2013, a large outbreak was reported on the archipelago of French Polynesia. In this study, we report the detection and molecular characterization of Zika virus for the first time in Chile from an outbreak among the inhabitants of Easter Island. A total of 89 samples from patients suspected of having ZIKV infection were collected between the period from January to May, 2014. Molecular diagnosis of the virus was performed by RT-PCR followed by the sequencing of the region containing the NS5 gene. A comparison of the viral nucleic acid sequence with those of other strains of ZIKA virus was performed using the MEGA software. Fifty-one samples were found positive for ZIKV by RT-PCR analysis. Further analysis of the NS5 gene revealed that the ZIKV strains identified in Easter Island were most closely related to those found in French Polynesia (99.8 to $99.9 \% \mathrm{nt}$ and $100 \%$ aa sequence identity). These results strongly suggest that the transmission pathway leading to the introduction of Zika virus on Easter Island has its origin in French Polynesia.
\end{abstract}

Keywords Zika virus · Easter Island · Outbreak · South Pacific · ZIKV

J. Fernández

jfernand@ispch.cl; jofernand@gmail.com

1 Subdepartment of Molecular Genetics, Public Health Institute of Chile, Santiago, Chile

2 Emergent and Hepatic Virus Laboratory, Public Health Institute of Chile, Santiago, Chile

3 Subdepartment of Virology, Public Health Institute of Chile, Santiago, Chile
Zika virus (ZIKV) is a mosquito-borne virus belonging to the family Flaviviridae and the genus Flavivirus. The Flaviviruses also include yellow fever, dengue, St. Louis encephalitis, West Nile, and Japanese encephalitis viruses [6]. ZIKV was first isolated from the blood of a sentinel rhesus monkey inhabiting the Zika Forest in Uganda [6]. Later on, ZIKV was isolated from a mosquito of the species Aedes africanus, obtained from the same locality of the Zika Forest. ZIKV has been isolated from several species of Aedes mosquito, notably, A. aegypti and A. albopictus [10]. A. aegypti is widely distributed in tropical and subtropical regions of the world $[6,11,12]$.

Clinically diagnosed ZIKV infections in human cases have been reported to include self-limiting acute febrile illnesses with fever, headache, myalgia, retro-orbital pain, arthralgia, conjunctivitis, and rash. These clinical presentations closely resemble those that are caused by dengue virus (DENV) and Chikungunya virus [6]. Serological studies and isolation of ZIKV strains have subsequently indicated that the virus has a wide geographical distribution, including regions in East and West Africa, South and South East Asia, and Micronesia [6], where an outbreak of Zika fever was reported on Yap Island [4]. In 2013, a Zika fever outbreak in French Polynesia was the largest ever reported for an arbovirus other than DENV at this location. Following this, there was a report of a Zika outbreak on the Cook Islands of New Caledonia [3, 12].

In Chile, at the end of 2000, the presence of A. aegypti on Easter Island was reported; the island is located on the east edge of the Polynesian Triangle, in the south Pacific Ocean, with a latitude of $27^{\circ} 9^{\prime} 10^{\prime \prime} \mathrm{S}$, and a longitude of $109^{\circ} 27^{\prime} 17^{\prime \prime} \mathrm{W}$ [13]. The closest continental point from this island is the Chilean coast, located at a distance of $3,800 \mathrm{~km}$. All of the inhabitants $(3,860)$ of this island live in a single rural village, Hanga Roa, on the western coast of 
Easter Island. In the year 2002, the first outbreak of dengue virus serotype 1 was reported, with 636 diagnosed cases of dengue fever [2, 13]. Subsequently, during surveillance activities on Easter Island in 2009, two cases of infection with dengue virus serotype 4 were detected [5]. Since the report of the first case of dengue virus, active surveillance for acute febrile illness has been coordinated by the Epidemiology Department of the Ministry of Health, with the active participation of the Hospital of Hanga Roa-the only health center located on the island, which also serves as a public health institute.

Here, we report the identification of ZIKV as the causative agent of the outbreak that started in January 2014 on Easter Island. A total of 89 blood samples were collected from suspected ZIKV-infected human patients who visited the emergency unit service of Hanga Roa Hospital, as they were being treated as suspected cases during the period from January to May 30, 2014. These patients complained of fever and maculopapular erythematous rash within the first five days after the onset of symptoms, along with at least one of the following symptoms: conjunctival hyperemia, arthralgia, and myalgia. For each patient, vital parameters such as age and sex, clinical presentation, the date and time of onset of symptoms, the date of sample collection, and the history of travel were recorded.

In order to confirm the diagnosis of suspected ZIKV infection, $5 \mathrm{~mL}$ of venous whole blood was collected from all of the suspected patients. The blood samples were centrifuged at $1500 \times g$ for $10 \mathrm{~min}$, and the sera obtained were stored at $-20{ }^{\circ} \mathrm{C}$ until further analysis. All of the serum samples were sent to the Public Health Institute of Chile for further virological analysis.

Viral RNA was extracted from $300 \mu \mathrm{L}$ of serum using an easyMAG extraction system (bioMérieux) [11]. A nested RT-PCR-based method described by Kuno et al. [9] was developed by the Public Health Institute of Chile to analyze the samples. In this study, a patient was considered positive for ZIKV if the sample tested positive in the RTPCR analysis described above.

The amplicons generated from the NS5 genes were sequenced in both directions using a BigDye Terminator v3.1 Cycle Sequencing Kit (Applied Biosystems, Foster City, CA, USA). Nucleotide sequences were obtained using an ABI PRISM 3500 Genetic Analyzer (Applied Biosystems). The sequence data were assembled and edited electronically using the Seqman, EditSeq and MegAlign programs (DNASTAR, Madison, WI). A maximum-likelihood (ML) phylogenetic tree was constructed for the NS5 gene with the K2 + G + I model using MEGA6 software [14].
A total of 89 serum samples from cases of suspected ZIKV infection cases were tested by RT-PCR. Of these, 51 samples tested positive for ZIKA. The ZIKV-negative serum samples were re-extracted and re-tested by nested RT-PCR. All of them tested negative for ZIKV when retested. The 51 ZIKA-positive cases in the present study corresponded to 42 adult ( $>16$ years) patients, and the rest ( 9 cases) were children $(<15$ years). Thirty-three $(64 \%)$ patients were female, and $18(36 \%)$ were male. None of the patients reported a history of recent travel outside the island. All of the samples (89) tested negative for dengue virus in real-time RT-PCR as described elsewhere [8].

In order to understand the genetic relationships between the different Zika virus strains, phylogenetic analysis of a region of 976 bp of the NS5 gene from the 51 samples that were positive by RT-PCR was performed using the maximum-likelihood (ML) algorithm for Chilean ZIKV. The sequences of the various Zika virus strains were retrieved from the NCBI database (GenBank accession no. KM078929-KM0778979). The viral strains from Easter Island were found to be most closely related to those found in French Polynesia (99.8 to $99.9 \%$ nt and $100 \%$ aa sequence identity) [1, 3, 11, 12] (Fig. 1). On the other hand, strains from Easter Island exhibited 98.1 to $98.3 \%$ nt and $100 \%$ aa sequence identity to the Cambodia 2010 (GenBank accession no. JN860885) and Micronesia 2007 (GenBank accession no. EU545988) strains [7, 10, 11]. Variations in the nucleotide sequence of the NS5 gene in some strains were located at the third nucleotide position of the codon, resulting in the conservation of amino acids.

Cao-Lormeau et al. reported the largest outbreak caused by an arbovirus other than DENV on the islands of French Polynesia [3]. They estimated that the number of suspected ZIKV infections was around 28,000 in February 2014, and the Easter Island index case was detected in January 2014. Based on the results obtained in this study, we assume that the transmission pathway for the introduction of ZIKV on Easter Island had its origin in French Polynesia.

Here, we report an outbreak of ZIKV for the first time on Easter Island. The results obtained in this study confirm the necessity of maintaining active virological and epidemiological surveillance on Easter Island due to the continuing risk posed by DENV and ZIKV. Furthermore, these findings documenting the spread of ZIKV have important public-health implications for the continued spread of this dengue-like disease, potentially to the western hemisphere. 


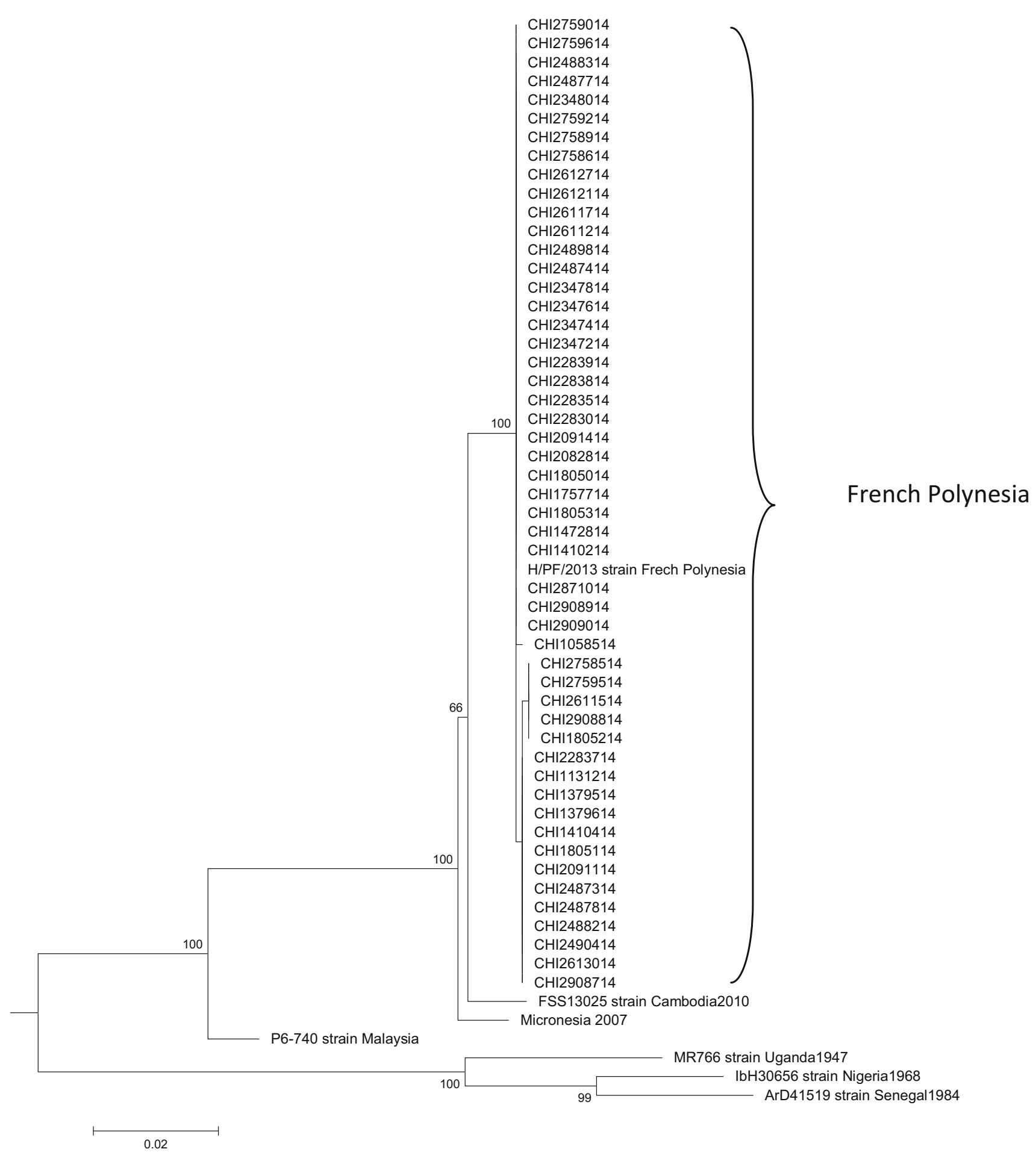

Fig. 1 Phylogenetic analysis of NS5 sequences derived from a Zika virus outbreak in Easter Island in 2014. The phylogenetic tree was based on a region of $976 \mathrm{bp}$ of the NS5 nucleotide sequence and was constructed using the maximum-likelihood method based on the
$\mathrm{K} 2+\mathrm{G}+\mathrm{I}$ model. The sequence of Spondweni virus (accession no. DQ859064) was used as outgroup. Bootstrap percentages based on 1,000 replicates are shown at the tree nodes. Evolutionary analysis was conducted using the software MEGA6 [14]

\section{References}

Arancibia and Liliana Ramos from the Subdepartment of Molecular Genetics of the Public Health Institute for excellent technical assistance. This study was supported by the Public Health Institute.
1. Baronti C, Piorkowski G, Charrel RN, Boubis L, Leparc-Goffart I, de Lamballerie X (2014) Complete coding sequence of zika 
virus from a French Polynesia outbreak in 2013. Genome Announc 2(3):e00500-14. doi:10.1128/genomeA.00500-14

2. Caceres C, Yung V, Araya P, Tognarelli J, Villagra E, Vera L, Fernández J (2008) Complete nucleotide sequence analysis of a Dengue-1 virus isolated on Easter Island, Chile. Arch Virol 153:1967-1970

3. Cao-Lormeau VM, Roche C, Teissier A, Robin E, Berry AL, Mallet HP, Sall AA, Musso D (2014) Zika virus, French Polynesia, South pacific, 2013. Emerg Infect Dis 20:1084-1086

4. Duffy MR, Chen TH, Hancock WT, Powers AM, Kool JL, Lanciotti RS, Pretrick M, Marfel M, Holzbauer S, Dubray C, Guillaumot L, Griggs A, Bel M, Lambert AJ, Laven J, Kosoy O, Panella A, Biggerstaff BJ, Fischer M, Hayes EB (2009) Zika virus outbreak on Yap Island, Federated States of Micronesia. N Engl J Med 360:2536-2543

5. Fernandez J, Vera L, Tognarelli J, Fasce R, Araya P, Villagra E, Roos O, Mora J (2011) Detection of dengue virus type 4 in Easter Island, Chile. Arch Virol 156:1865-1868

6. Haddow AD, Schuh AJ, Yasuda CY, Kasper MR, Heang V, Huy R, Guzman H, Tesh RB, Weaver SC (2012) Genetic characterization of Zika virus strains: geographic expansion of the Asian lineage. PLoS Negl Trop Dis 6:e1477

7. Heang V, Yasuda CY, Sovann L, Heang V, Yasuda CY, Sovann L, Haddow AD, Travassos da Rosa AP, Tesh RB, Kasper MR (2012) Zika virus infection, Cambodia, 2010. Emerg Infect Dis 18:349-351
8. Johnson B, Russell B, Lanciotti R (2005) Serotype-specific detection of dengue viruses in a four multiplex real-time reverse transcriptase PCR assay. J Clin Microbiol 43:4977-4983

9. Kuno G, Chang GJ, Tsuchiya KR, Karabatsos N, Cropp CB (1998) Phylogeny of the genus Flavivirus. J Virol 72:73-83

10. Lanciotti RS, Kosoy OL, Laven JJ, Velez JO, Lambert AJ, Johnson AJ, Stanfield SM, Duffy MR (2008) Genetic and serologic properties of Zika virus associated with an epidemic, Yap State, Micronesia, 2007. Emerg Infect Dis 14:1232-1239

11. Musso D, Nhan T, Robin E, Roche C, Zisou K, Shan Yan A, CaoLormeau VM, Broult J (2014) Potential for Zika virus transmission through blood transfusion demonstrated during an outbreak in French Polynesia, November 2013 to February 2014. Euro Surveill 19. pii: 20761

12. Musso D, Nilles EJ, Cao-Lormeau VM (2014) Rapid spreading of emerging Zika virus in the Pacific area. Clin Microbiol Infect 20:(10):0595-6. doi:10.1111/1469-0691.12707

13. Perret C, Abarca K, Ovalle J, Ferrer P, Godoy P, Olea A, Aguilera X, Ferrés M (2003) Dengue-1 virus isolation during first dengue fever outbreak on Easter Island, Chile. Emerg Infect Dis 9:1465-1467

14. Tamura K, Stecher G, Peterson D, Filipski A, Kumar S (2013) MEGA6: Molecular Evolutionary Genetics Analysis version 6.0. Mol Biol Evol 30:2725-2729 